\title{
Effectiveness of group medical visits for improving diabetes care: a systematic review and meta-analysis
}

\author{
Laura Housden MN-NP, Sabrina T. Wong RN PhD, Martin Dawes MBBS PhD
}

\begin{abstract}
Background: Group medical visits, whereby health care professionals meet with groups of patients who have the same disease, have been introduced in primary care as a way to meet the increasing demand for health care delivery to patients with chronic diseases. We performed a systematic review and metaanalysis of the evidence on the effectiveness of such visits for patients with diabetes.
\end{abstract}

Methods: We conducted a systematic review of all relevant studies published from 1947 to February 2012 identified in a search of electronic databases and grey literature. We included randomized controlled trials (RCTs) and observational studies published in English that included patients aged $16-80$ years with type 1 or 2 diabetes and that had group medical visits as the intervention. These studies were assessed for methodologic quality.
We included data only from the RCTs in the meta-analysis.

Results: Of the 94 studies identified, we selected 26 that met our inclusion criteria, 13 of which were RCTs. Group medical visits had a positive effect on clinical and patient-reported outcomes, with significant reductions in glycated hemoglobin $\left(\mathrm{HbA}_{1 \mathrm{c}}\right.$ reduction $-0.46 \%, 95 \%$ confidence interval $-0.80 \%$ to $-0.31 \%$ ). We were unable to assess the effect of group medical visits on processes of care because of an insufficient number of RCTs that reported on this outcome.

Interpretation: Group medical visits for patients with diabetes were found to be effective in terms of reducing $\mathrm{HbA}_{1 \mathrm{c}}$. The results of our metaanalysis suggest that wider implementation of group medical visits for patients with diabetes will have a positive effect on patient outcomes.
I ncreasing evidence shows that strengthening the foundation of primary health care will lead to improved health and provide better management for people with one or more chronic conditions. ${ }^{1}$ In Canada, increased attention on the primary health care system is particularly important given the growing number of people living with one or more chronic conditions. ${ }^{2}$ The move to renew and redesign primary care has led to a number of innovations, including group medical visits. ${ }^{3}$

Group medical visits are a format for health care delivery whereby medical appointments are offered to a group of patients with the same disease instead of the traditional one-to-one patient-provider format. ${ }^{4}$ During the group visit, patients receive a health evaluation and educational information about their condition and about the prevention of complications and disease progression, and they may have prescriptions, referrals and laboratory tests ordered. The visit is usually facilitated by a physician or a nurse practitioner and may involve other interdisciplinary team members such as a registered nurse, nutritionist and pharmacist. $^{5}$

Group medical visits offer an ideal format for patients with chronic diseases because they allow health care practitioners to provide care to 12-15 patients in one appointment and enable patients to interact with people who share their condition. In Canada, group medical visits are increasingly being used to provide primary health care to patients with diabetes. ${ }^{3}$ Type 1 and type 2 diabetes affect about $6.8 \%$ of the Canadian population. ${ }^{6}$ Social support from peers with diabetes has been shown to improve some clinical outcomes. ${ }^{7,8}$

Although health care providers have reported this care model to be an effective way to deliver care, ${ }^{9-12}$ data are limited and differ on the impact of group medical visits on patient outcomes. We conducted a systematic review and metaanalysis to measure the effect of group medical visits on biophysical, process-of-care and patient-reported outcomes among patients with type 1 and 2 diabetes.
Competing interests: None declared.

This article has been peer reviewed.

Correspondence to: Laura Housden, laura.housden@telus.net

CMAJ 2013. DOI:10.1503 /cmaj.130053 


\section{Methods}

We used the PICO (population, intervention, comparison and outcome) approach to develop the research question for our systematic review - population: patients with type 1 or 2 diabetes; intervention: group medical visits; comparison: usual care; outcomes: biophysical, patient-reported and process-of-care outcomes.

\section{Literature search}

We conducted a comprehensive search of the following electronic databases from inception through February 2012: MEDLINE (PubMed), CINAHL, Biosis, ProQuest Dissertations and Theses, Embase, Web of Science, Psych Info and the Cochrane Database of Systematic Reviews. We also searched various sources of grey literature. Bibliographies of selected articles were manually searched for additional studies. Details of our search strategies are available in Appendix 1 (available at www.cmaj.ca/lookup/suppl/doi :10.1503/cmaj.130053/-/DC1). A librarian was consulted to review the search strategy.

\section{Study selection}

A 3-step process was used to determine the eligibility of studies for our review. First, the title of relevant articles were independently screened by each of us. Second, if titles were deemed relevant, abstracts were independently reviewed by 2 of us (L.H. and either S.T.W. or M.D.). Finally, if abstracts were deemed relevant, full-text articles were independently reviewed by 2 of us (as described above). Decisions regarding inclusion and exclusion of studies were made by consensus between the 2 reviewers; disagreements were resolved by the third reviewer as required.

We included randomized controlled trials (RCTs) and observational studies published in English or translated into English that included patients aged 16-80 years with type 1 or 2 diabetes and had group medical visits as the intervention. We excluded studies in which the intervention was for educational purposes or did not include a health care provider who could diagnose, prescribe, make referrals and order laboratory tests.

Multiple articles from the same study or group of patients were classified as "kinned" articles. We grouped kinned articles together and counted them as one study.

\section{Data extraction}

We collected data on study characteristics, participant demographics, and clinical and patientreported outcomes. Where possible, sample size and post-intervention means and standard deviations (SDs) were extracted for both the interven- tion and usual-care groups. We extracted data from the observational studies to inform the discussion. Data were initially extracted by one of us (L.H.) and checked by the others (S.T.W., M.D.) to ensure accuracy.

\section{Assessment of bias}

We assessed RCTs for risk of bias using the Cochrane Risk of Bias Tool. ${ }^{13}$ One of us (L.H.) completed the full quality assessment. Congruency of the assessment was ensured by having a second reviewer (S.T.W.) independently assess quality of 5\% of the included studies. A sensitivity analysis was performed in which we excluded studies that had 2 or more items with a high risk of bias. Because some articles included patients with either type 1 or type 2 diabetes, we conducted an additional sensitivity analysis for glycated hemoglobin $\left(\mathrm{HbA}_{\mathrm{cc}}\right)$ in which we excluded studies that included only patients with type 1 diabetes as well as studies in which the type of diabetes was unclear. Overall effect size, significance and funnel plots were examined for $\mathrm{HbA}_{1 \mathrm{c}}$.

\section{Data synthesis}

We included only RCTs in the meta-analysis. We analyzed the data from RCTs using Review Manager software (RevMan, version 5.1, Nordic Cochrane Centre). For each RCT, the effect size was calculated to determine the mean differences between the intervention and control groups at the longest reported time after the intervention.

Mean differences were first pooled into a fixed-effects model. A $\chi^{2}$ test for heterogeneity was performed; when significant heterogeneity was found $\left(I^{2}>25 \%\right)$, the analysis was recalculated with a random-effects model. The mean differences were weighted and pooled following Hedges' method for calculating standardized mean differences. ${ }^{14}$

When measures of dispersion were not reported for outcome data, we used baseline SDs or calculated SDs from reported $p$ values. When no baseline SD or $p$ values were reported, we estimated SDs from the baseline range data. When examining these estimated SDs, we found that they were conservative estimates of the value; a sensitivity analysis in which we removed studies with uncertain SDs yielded improved $\mathrm{HbA}_{\mathrm{cc}}$ outcomes with a decrease in effect size.

We performed a meta-regression analysis to determine (a) if the length of time patients spent attending group medical visits was related to effect size and (b) if the number of group visits a patient attended in a year was related to effect size. To examine the number of group visits attended per year, we created an "intensity" 
value by dividing the number of appointments by the number of years of the intervention. For the meta-regression analysis, we used Stata software, version 12.1 (StataCorp LP).

\section{Results}

We identified 92 potentially eligible articles. The most common reasons for exclusion were that the intervention did not involve a health care provider who could prescribe, diagnose, assess and refer patients; the article was a narrative or commentary based on other research studies; the study did not include a group medical visit as the intervention; and the article was not in English. A total of 26 studies met our inclusion criteria (Figure 1)..$^{5,15-45}$

\section{Study characteristics}

The characteristics of the 13 RCTsincluded in the meta-analysis are summarized in Table $1^{15-33}$ (for characteristics of all 26 studies, see Appendix 2, available at www.cmaj.ca/lookup/suppl/doi $: 10.1503 / \mathrm{cmaj} .130053 /$ /DC1). The number of studies published after 2002 increased substantially ( 4 studies before 2002, 12 between 2002 and 2007, and 16 between 2008 and 2012). One document was a doctoral dissertation, completed in $2011 .^{43}$ Most of the studies $(n=20)$ were conducted in the United States, ${ }^{5,15-23,25-28,33,34,36-43}$ with the remainder conducted in Europe (Austria $n=1,{ }^{44}$ France $n=1,{ }^{35}$ Italy $n=3^{29-32,45}$ Norway $n=1^{24}$ ). Samples ranged in size from 37 to 707 participants. Three studies included fewer than 50 patients, and 6 had more than 200; the remainder had between 50 and 100 patients ( $n=7$ studies) or between 100 and 200 patients $(n=10)$.

Of the total 4652 patients, 3112 received group care or attended group medical visits as an intervention. The mean age of participants in the studies that reported this information was 59.3 years, and $56 \%$ of participants attending group medical visits were men.

\section{Study quality}

A summary of the risk-of-bias assessment of the 13 RCTs can be found in Table 2. The amount of bias varied across the trials. Only one had a low risk of bias in most areas. ${ }^{22}$ The other RCTs either did not report enough information for bias to be assessed or had 2 or more areas assessed as a high source of bias.

\section{Clinical outcomes}

Eleven of the RCTs reported $\mathrm{HbA}_{\mathrm{lc}}$ data at baseline. The baseline values did not differ significantly between the studies (weighted mean difference $-0.09,95 \%$ confidence interval $[\mathrm{CI}]$
-0.29 to 0.11 ). Only 10 studies reported $\mathrm{HbA}_{1 c}$ data that could be included in our meta-analysis. Pooled analysis of $\mathrm{HbA}_{\mathrm{lc}}$ values after the intervention period showed significantly lower values among the patients attending group medical visits (weighted mean difference $-0.46,95 \% \mathrm{CI}$ -0.80 to -0.13 ) (Table 3, Figure 2).

In the meta-regression analysis, we found that duration of treatment directly affected patients' $\mathrm{HbA}_{1 \mathrm{c}}$ values. Patients who attended group medical visits for longer periods had better $\mathrm{HbA}_{1 \mathrm{c}}$ outcomes. For every year increase in the duration of treatment, there was a decrease in effect size of 0.25 , which indicated a drop in $\mathrm{HbA}_{\mathrm{lc}}$ of one quarter of $1 \%$. When we examined whether the frequency of group visits had an effect on $\mathrm{HbA}_{1 \mathrm{c}}$ outcomes, it did not explain the difference in the effect size, which indicated that the duration of treatment had a greater effect on $\mathrm{HbA}_{1 \mathrm{c}}$ outcomes than the number of appoint-

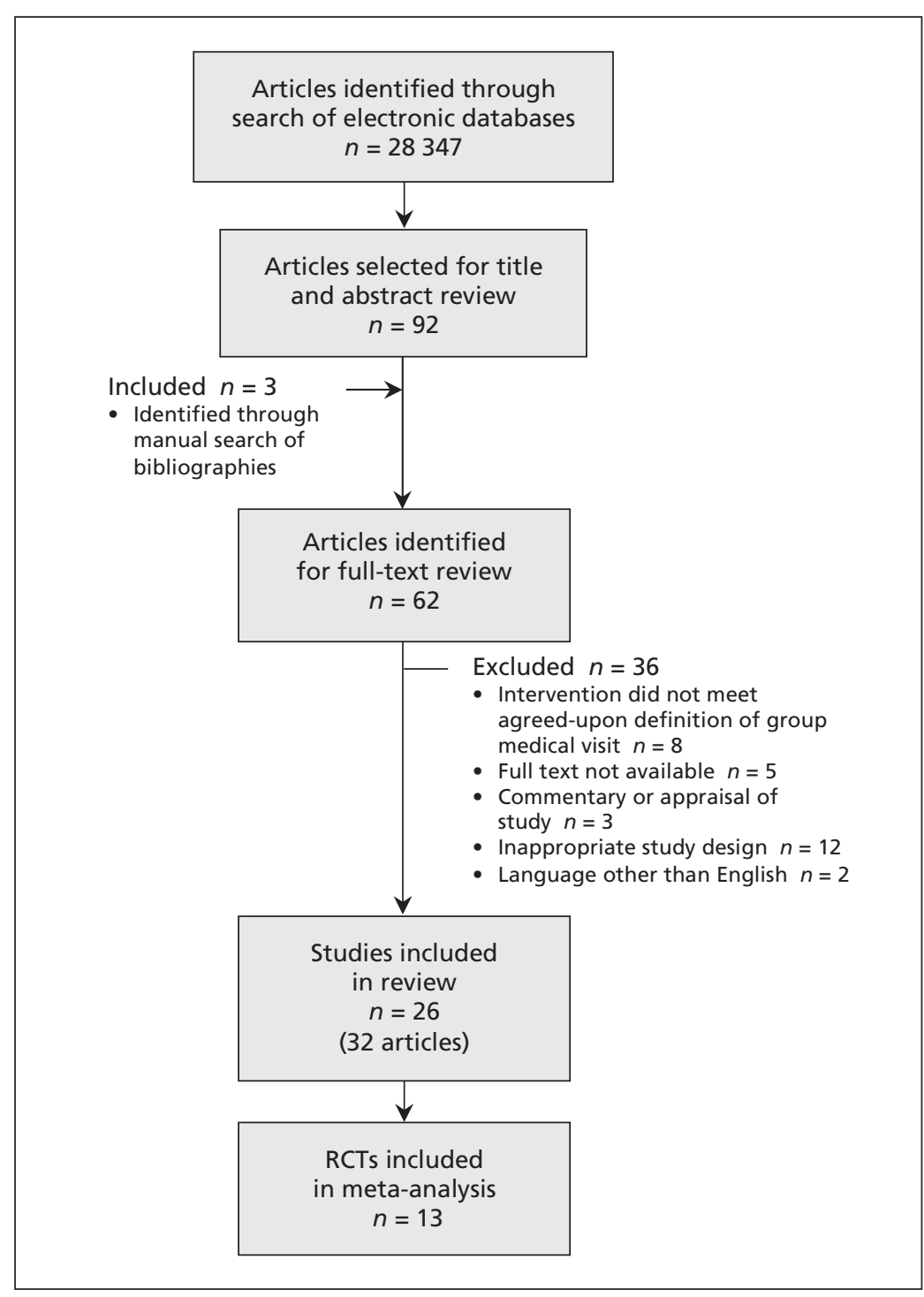

Figure 1: Selection of studies. RCT = randomized controlled trial. 


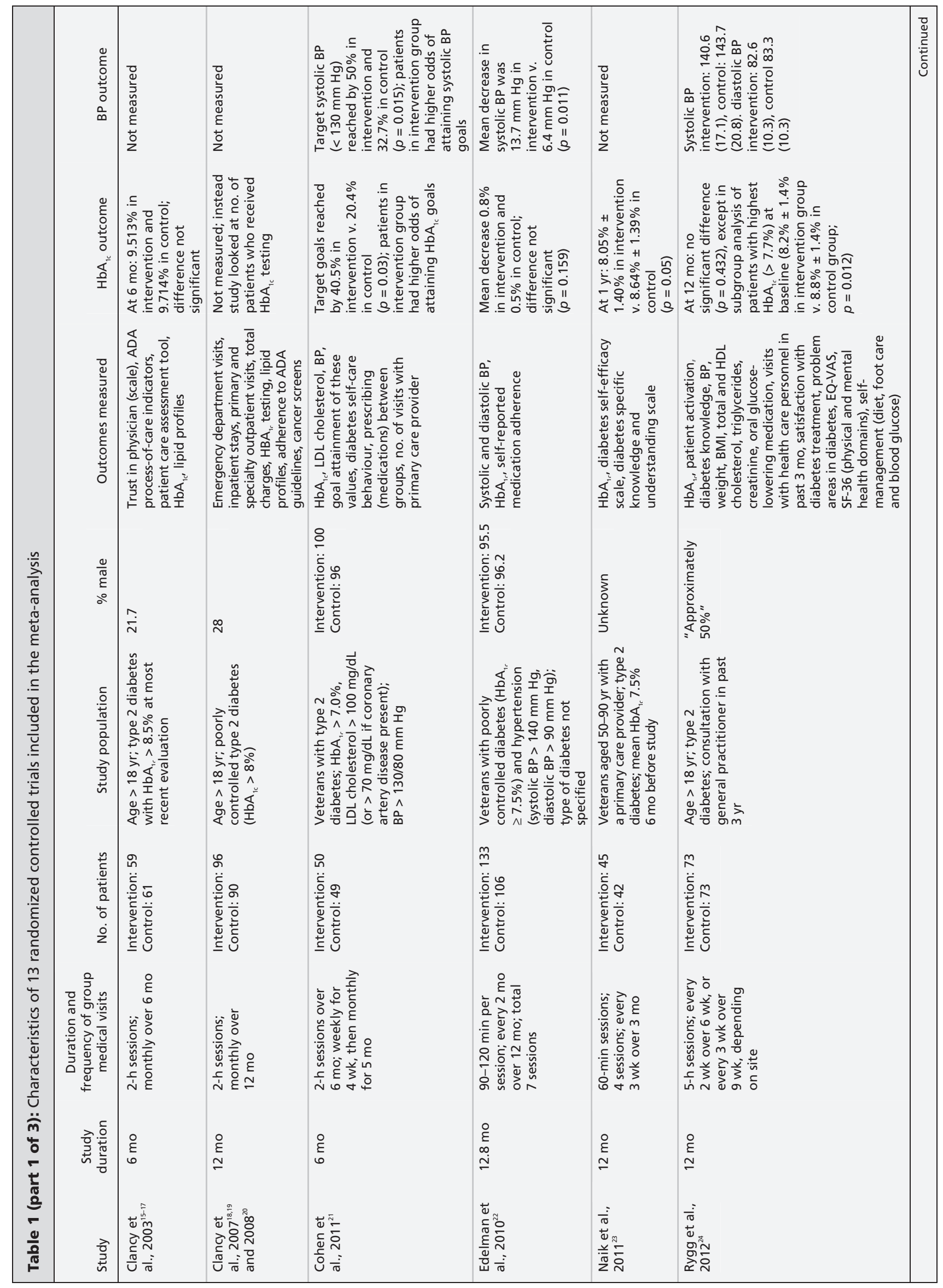




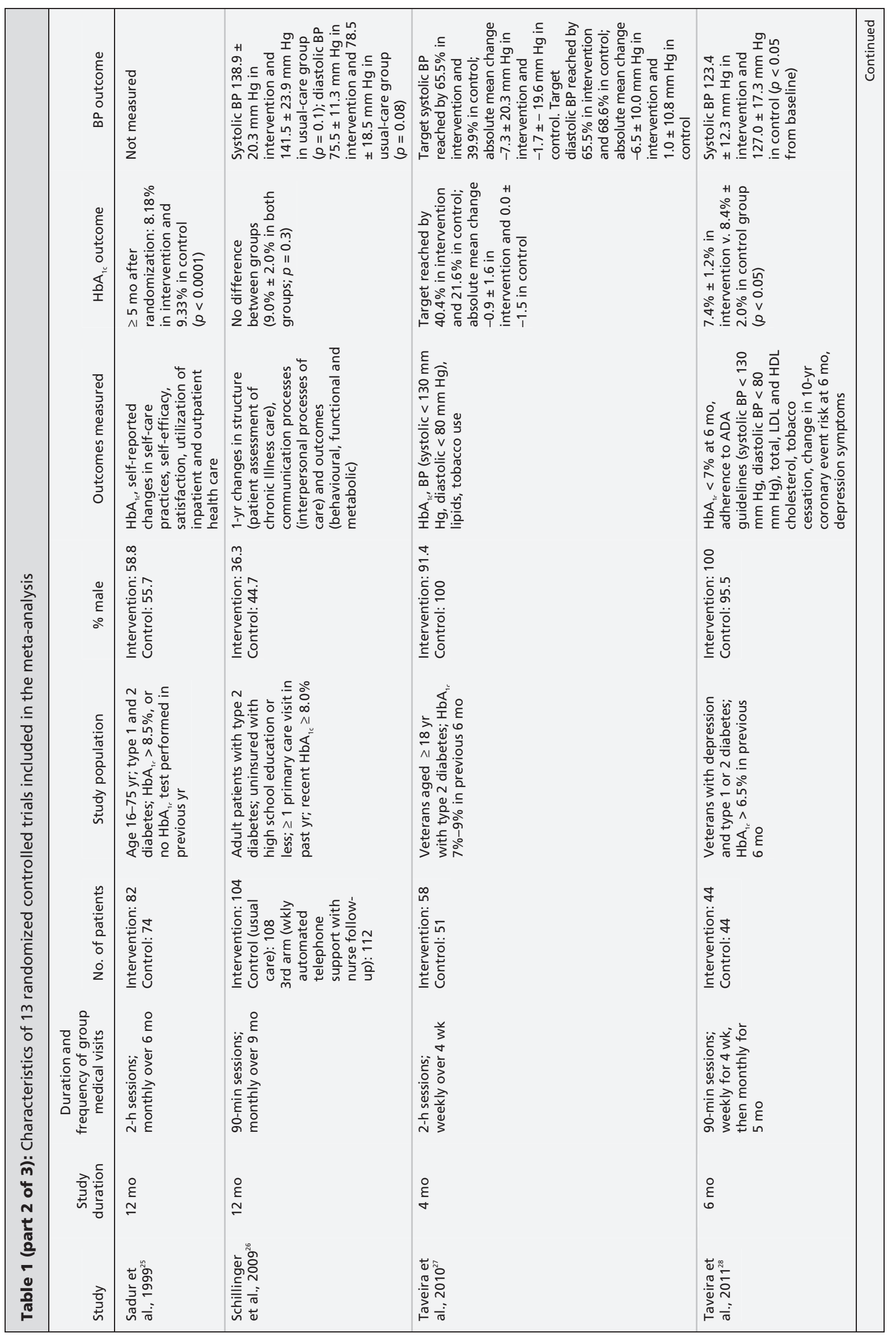




\begin{tabular}{|c|c|c|c|c|c|}
\hline 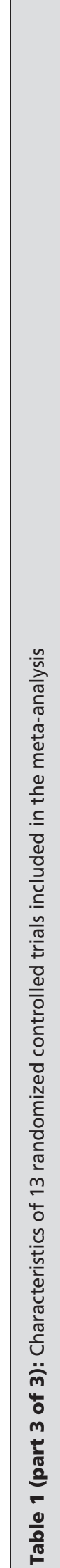 & 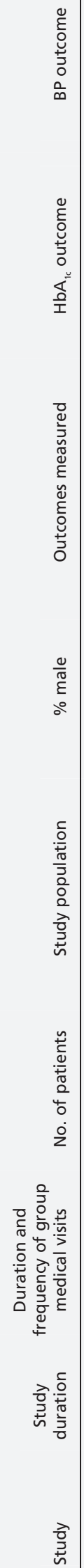 & 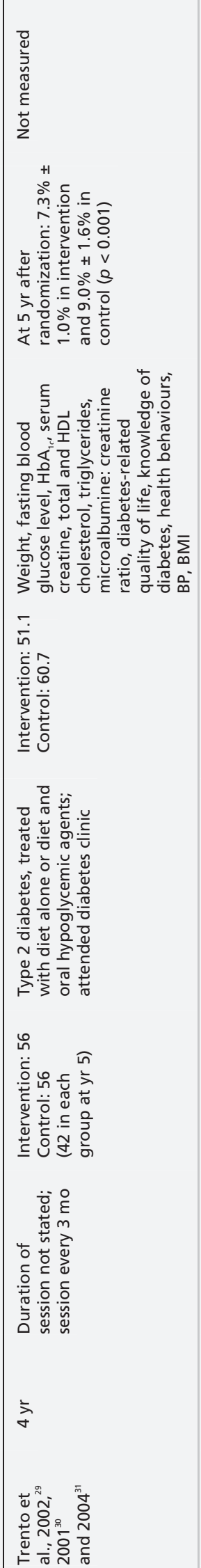 & 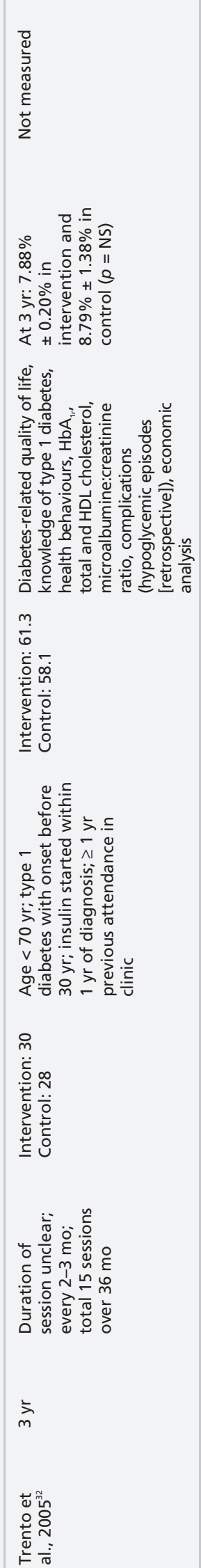 & 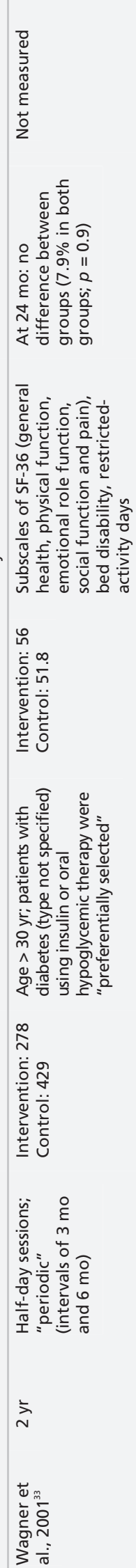 & 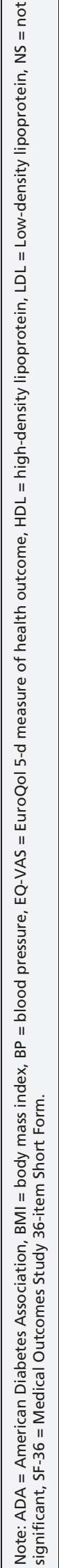 \\
\hline
\end{tabular}


ments attended per year. We did not analyze other attributes of group visits using metaregression techniques because the data were not consistently reported in the RCTs.

When we excluded studies with 2 or more methodologic features assessed as a high source of bias, the overall effect of group medical visits on $\mathrm{HbA}_{1 \mathrm{c}}$ improved (weighted mean difference $-0.62,95 \%$ CI -1.23 to -0.01$)$. When we excluded studies with 3 or more features assessed as a high source of bias, the effect size did not change significantly $(-0.47,95 \% \mathrm{CI}$ -0.94 to 0.00 ). When we excluded studies that had only patients with type 1 diabetes, the effect size increased $(-0.58,95 \% \mathrm{CI}-1.12$ to -0.04$)$.

Five of the RCTs evaluated the effects of group medical visits on systolic blood pressure, and 4 assessed the effects on diastolic pressure. No statistically significant effect on either type of blood pressure was found in the metaanalysis (Table 3; see also Appendix 3, available at www.cmaj.ca/lookup/suppl/doi:10.1503/cmaj .130053/-/DC1).

Group medical visits had a slightly positive effect on patients' weight, but no effect on body mass index; the effect on weight was not statistically significant. A negative effect of group medical visits on total and high-density lipoprotein cholesterol levels was noted; however, the effects were minimal (Table 3, Appendix 3).

\section{Other outcomes}

Patients who attended group medical visits reported improvements in quality of life, as measured by the Diabetes Quality of Life Question- naire $^{46}$ (weighted mean difference $-29.30,95 \% \mathrm{CI}$ -60.64 to 2.05 ); however, the results were limited to 2 RCTs and were not statistically significant.

Data on process-of-care outcomes in the RCTs were insufficient to include them in the meta-analysis. In our synthesis of findings from all 26 studies, we noted reports on aspects of patients' engagement in their health care, including positive outcomes in the domain of selfcare, ${ }^{21,25}$ physical activity, ${ }^{39}$ the setting and achievement of measurable goals,,$^{21,34,39}$ patient knowledge, ${ }^{24,31,32,41,44}$ self-efficacy ${ }^{23,25}$ and selfmanagement. ${ }^{24,26,3,4,36,40,44}$

\section{Interpretation}

Our meta-analysis showed that group medical visits for patients with diabetes led to significant reductions in $\mathrm{HbA}_{1 \mathrm{c}}$. Small decreases have been shown to have substantial clinical impacts: a $1.0 \%$ reduction in $\mathrm{HbA}_{1 \mathrm{c}}$ may be associated with a $37 \%$ decrease in microvascular complications, up to a $14 \%$ reduction in the incidence of myocardial infarction and a $21 \%$ decrease in the risk of death from diabetes. ${ }^{47}$

Patients with diabetes are known to be at increased risk of cardiovascular disease and cardiovascular-related death. ${ }^{48,49}$ Although not statistically significant, the reductions in systolic and diastolic blood pressure among patients attending group medical visits are of interest. Many lifestyle modifications such as weight reduction, dietary changes, physical activity and alcohol consumption have been found to reduce systolic blood pressure by $2-8 \mathrm{~mm} \mathrm{Hg} .{ }^{50} \mathrm{~A}$ reduction of

Table 2: Risk-of-bias assessment of the randomized controlled trials

\begin{tabular}{|c|c|c|c|c|c|c|c|}
\hline Study & $\begin{array}{c}\text { Random } \\
\text { sequence } \\
\text { generation } \\
\text { (selection bias) }\end{array}$ & $\begin{array}{l}\text { Allocation } \\
\text { concealment } \\
\text { (selection bias) }\end{array}$ & $\begin{array}{c}\text { Blinding } \\
\text { of participants } \\
\text { and personnel } \\
\text { (performance bias) }\end{array}$ & $\begin{array}{c}\text { Blinding } \\
\text { of outcome } \\
\text { assessment } \\
\text { (detection bias) }\end{array}$ & $\begin{array}{l}\text { Incomplete } \\
\text { outcome data } \\
\text { (attrition bias) }\end{array}$ & $\begin{array}{c}\text { Selective } \\
\text { reporting } \\
\text { (reporting bias) }\end{array}$ & $\begin{array}{l}\text { Other } \\
\text { bias }\end{array}$ \\
\hline Clancy et al. ${ }^{15-17}$ & High & Unclear & High & Unclear & Unclear & Unclear & Unclear \\
\hline Clancy et al. ${ }^{18-20}$ & Low & Low & Low & High & Unclear & Unclear & Unclear \\
\hline Cohen et al. ${ }^{21}$ & High & High & High & Unclear & Unclear & Unclear & Unclear \\
\hline Naik et al. ${ }^{23}$ & Low & Low & Unclear & High & Low & Unclear & Unclear \\
\hline Rygg et al., ${ }^{24}$ & Low & Low & Low & Unclear & Low & Unclear & Unclear \\
\hline Sadur et al. ${ }^{25}$ & High & High & High & Unclear & Unclear & Unclear & Unclear \\
\hline Schillinger et al. ${ }^{26}$ & Low & High & High & Unclear & Low & Unclear & Unclear \\
\hline Taveira et al. ${ }^{27}$ & High & Unclear & Unclear & Unclear & Unclear & Unclear & Unclear \\
\hline Wagner et al. ${ }^{33}$ & High & High & High & Unclear & Unclear & High & Unclear \\
\hline
\end{tabular}


$2 \mathrm{~mm} \mathrm{Hg}$ in diastolic blood pressure has been associated with a $6 \%$ decrease in the risk of coronary heart disease and a $15 \%$ reduction in stroke and transient ischemic attacks. ${ }^{51}$

An additional factor to consider when caring for patients with diabetes is their quality of life. Although only 2 of the RCTs measured this outcome using the Diabetes Quality of Life Questionnaire, the aspects of patients' quality of life examined in many of the other studies were similar to the domains covered in the questionnaire.

Only 2 of the RCTs examined the risk of hypoglycemic events associated with group medical visits. ${ }^{22,32}$ Studies have shown that intensive glucose-lowering therapy among patients with diabetes may increase the risk of morbidity and mortality owing to hypoglycemic events..$^{52,53}$

Table 3: Pooled analysis of the effect of group medical visits on clinical outcomes reported in randomized controlled trials

\begin{tabular}{|lcc|}
\hline Outcome & $\begin{array}{c}\text { No. } \\
\text { of trials }\end{array}$ & $\begin{array}{c}\text { Weighted mean } \\
\text { difference }(95 \% \mathrm{Cl})\end{array}$ \\
\hline $\mathrm{HbA}_{1 \mathrm{c}}$ & 10 & $-0.46(-0.80$ to -0.13$)$ \\
\hline Systolic BP & 5 & $-2.81(-6.84$ to 1.21$)$ \\
\hline Diastolic BP & 4 & $-1.02(-2.71$ to 0.67$)$ \\
\hline Total cholesterol & 3 & $0.04(-0.21$ to 0.30$)$ \\
\hline HDL cholesterol & 3 & $0.01(-0.07$ to 0.10$)$ \\
\hline Triglycerides & 3 & $-0.01(-0.41$ to 0.38$)$ \\
\hline Weight & 3 & $-0.50(-3.87$ to 2.88$)$ \\
\hline BMI & 4 & $0.05(-0.90$ to 1.00$)$ \\
\hline $\begin{array}{l}\text { Note: BMI = body mass index, BP }=\text { blood pressure, } \mathrm{Cl}=\text { confidence interval, HDL }=\text { high- } \\
\text { density lipoprotein. }\end{array}$ & \\
\hline
\end{tabular}

\section{Limitations}

There were few long-term studies examining the effectiveness of group medical visits for diabetes care. Fifteen of the 26 studies were 12 months or less in duration, and 6 studies were up to 2 years in duration. The study with the longest duration followed patients for 5 years after the intervention. Therefore, the long-term or sustainable outcomes of group medical visits are unclear, and it is difficult to know if the outcomes were maintained for a substantial length of time after the intervention.

Another limitation was that we restricted our search to include only published studies. We realize that studies showing a lack of effect may not have been published. We also included only articles written in English or translated into English, thereby excluding 2 studies not published in English.

Many of the studies involved specific populations of patients, such as those with low incomes, those with different ethnic backgrounds and veterans. Although group medical visits may work for populations with specific characteristics, the mixed results indicate that further examination of the types of populations and types of delivery models is needed.

\section{Conclusion}

Group medical visits for patients with diabetes were found to be effective in terms of reducing $\mathrm{HbA}_{1 \mathrm{c}}$. The results of our meta-analysis, combined with the other benefits reported by patients and providers, suggest that wider implementation of group medical visits for patients with diabetes will have a positive effect on patient outcomes.

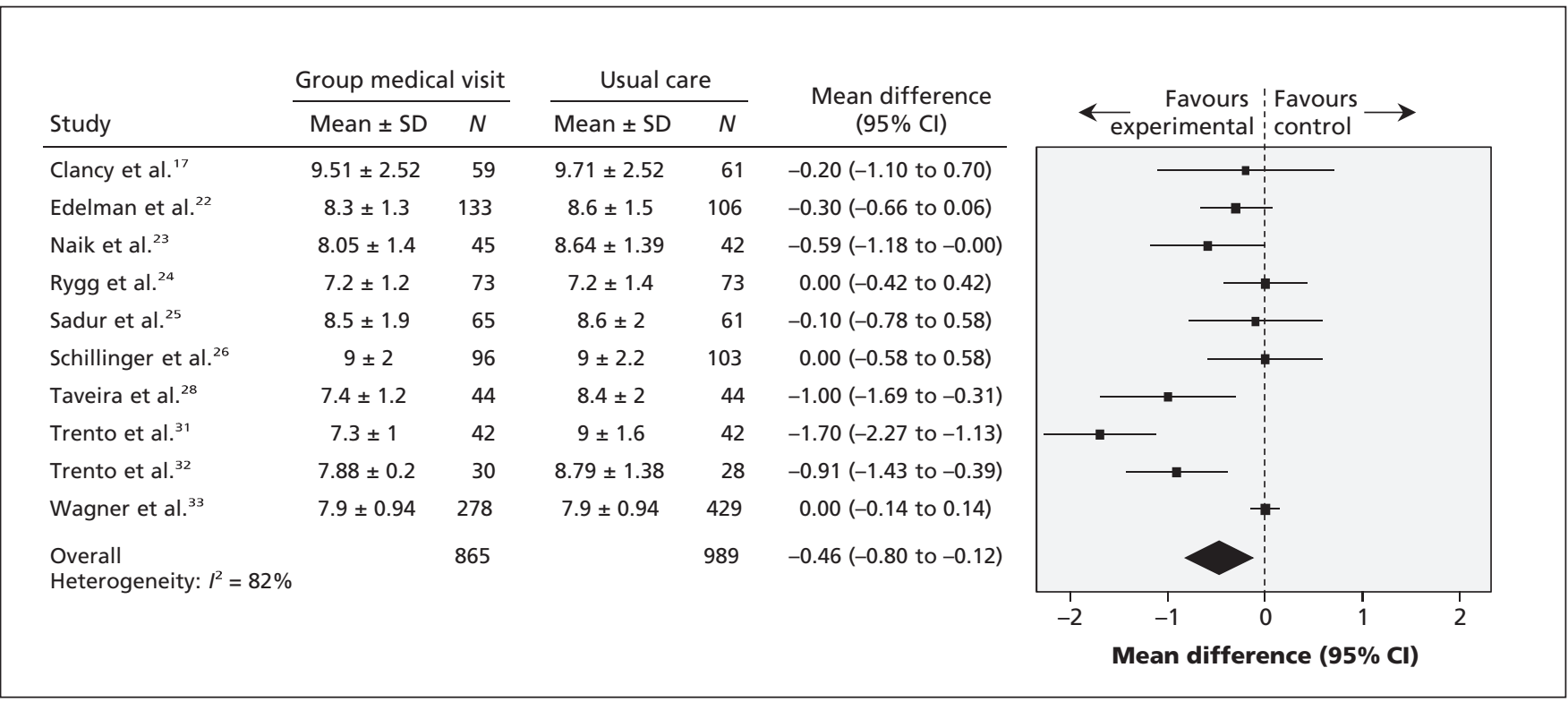

Figure 2: Pooled analysis of the effect of group medical visits versus usual care for patients with diabetes on glycated hemoglobin $\left(\mathrm{HbA}_{1 \mathrm{c}}\right)$ reported in randomized controlled trials. A weighted mean difference of less than zero indicates a positive effect of group medical visits. $\mathrm{Cl}=$ confidence interval, $\mathrm{SD}=$ standard deviation. 


\section{References}

1. Epping-Jordan JE, Pruitt S, Bengoa R, et al. Improving the quality of health care for chronic conditions. Qual Saf Health Care 2004;13:299-305.

2. Fortin M, Bravo G, Hudon C, et al. Prevalence of multimorbidity among adults seen in family practice. Ann Fam Med 2005;3:223-8.

3. Practice Support Program. Vancouver (BC): Impact BC; 2008 Available: www.impactbc.ca/what-we-do/projects/practicesupport-program (accessed 2010 Apr. 18)

4. Bodenheimer T, Grumbach K. Alternatives to the 15-minute visit. Improving primary care: strategies and tools for a better practice. New York (NY): McGraw-Hill; 2007:120.

5. Kirsh S, Watts S, Pascuzzi K, et al. Shared medical appointments based on the chronic care model: a quality improvement project to address the challenges of partients with diabetes with high cardiovascular risk. Qual Saf Health Care 2007;16:349-53.

6. Diabetes in Canada. facts and figures from a public health perspective. Ottawa (ON): Public Health Agency of Canada; 2011

7. van Dam HA, van der Horst F, Knoops L, et al. Social support in diabetes: a systematic review of controlled intervention studies. Patient Educ Couns 2005;59:1-12.

8. Smith SM, Paul G, Kelly A, et al. Peer support for patients with type 2 diabetes: cluster randomised controlled trial. BMJ 2011; 342(d715).

9. Scott JC, Robertson BJ. Kaiser Colorado's Cooperative Health Care Clinic: a group approach to patient care. Manag Care $Q$ 1996;4:41-5

10. Beck A, Scott J, Williams P, et al. A randomized trial of group outpatient visits for chronically ill older HMO members: the Cooperative Health Care Clinic. J Am Geriatr Soc 1997;45:543-9.

11. Bronson DL, Maxwell RA. Shared medical appointments: increasing patient access without increasing physician hours. Cleve Clin J Med 2004;71:369-70.

12. Bartley KB, Haney R. Shared medical appointments: improving access, outcomes, and satisfaction for patients with chronic cardiac diseases. J Cardiovasc Nurs 2010;25:13-9.

13. Higgins JPT, Altman DG, editors. Cochrane handbook for systematic reviews of interventions. Version 5.0.0 (updated February 2008). London (UK): The Cochrane Collaboration; 2008.

14. Higgins JPT, Green S, editors. Cochrane handbook for systematic reviews of interventions. Version 5.1.0 (updated March 2011). London (UK): The Cochrane Collaboration; 2011.

15. Clancy DE, Brown S, Magruder K, et al. Group visits in medically and economically disadvantaged patients with type 2 diabetes and their relationships to clinical outcomes. Top Health Inf Manage 2003;24:8-14

16. Clancy DE, Cope D, Magruder K, et al. Evaluating group visits in an uninsured or inadequatly insured patient population with uncontrolled type 2 diabetes. Diabetes Educ 2003;29:292-302.

17. Clancy DE, Cope D, Magruder K, et al. Evaluating concordance to American Diabetes Association standards of care for type 2 diabetes through group visits in an uninsured or inadequately insured patient population. Diabetes Care 2003;26:2032-6.

18. Clancy DE, Yeager D, Huang P, et al. Further evaluating the acceptability of group visits in an uninsured or inadequately insured patient population with uncontrolled type 2 diabetes. Diabetes Educ 2007;33:309-14.

19. Clancy DE, Huang P, Okonofua E, et al. Group visits: promoting adherence to diabetes guidelines. J Gen Intern Med 2007;22:620-4.

20. Clancy DE, Dismuke C, Magruder K, et al. Do diabetes group visits lead to lower medical care charges? Am J Manag Care 2008; $14: 39-44$

21. Cohen LB, Taveira T, Khatana S, et al. Pharmacist-led shared medical appointments for multiple cardiovascular risk reduction in patients with type 2 diabetes. Diabetes Educ 2011;37:801-12.

22. Edelman D, Fredrickson S, Melnyk S, et al. Medical clinics versus usual care for patients with both diabetes and hypertension: a randomized trial. Ann Intern Med 2010;152:689-96.

23. Naik AD, Palmer N, Petersen N, et al. Comparative effectiveness of goal setting in diabetes mellitus group clinics: randomized clinical trial. Arch Intern Med 2011;171:453-9.

24. Rygg L $\varnothing$, Rise M, Gronning K, et al. Efficacy of ongoing group based diabetes self-management education for patients with type 2 diabetes mellitus. A randomized control trial. Patient Educ Couns 2012;86:98-105.

25. Sadur CN, Moline N, Costa M, et al. Diabetes management in a health maintenance organization. Efficacy of care management using cluster visits. Diabetes Care 1999;22:2011-7.

26. Schillinger D, Handley M, Wang F, et al. Effects of self-management support on structure, process and outcomes among vulnerable patients with diabetes: a three-arm practical clinical trial. Diabetes Care 2009;32:559-66.

27. Taveira TH, Friedmann P, Cohen, et al. Pharmacist-led group medical appointment model in type 2 diabetes. Diabetes Educ 2010;36:109-17.
28. Taveira TH, Dooley A, Cohen L, et al. Pharmacist-led group medical appointments for the management of type 2 diabetes with comorbid depression in older adults. Ann Pharmacother 2011;45:1346-55.

29. Trento M, Passera P, Baiardi M, et al. Lifestyle intervention by group care prevents deterioration of type II diabetes: a 4-year randomized controlled clinical trial. Diabetologia 2002;45 1231-9

30. Trento M, Passera P, Tomalino M, et al. Group visits improve metabolic control in type 2 diabetes: a 2-year follow-up. Diabetes Care 2001;24:995-1000.

31. Trento M, Passera P, Borgo E, et al. A 5-year randomized controlled study of learning, problem solving ability, and quality of life modifications in people with type 2 diabetes managed by group care. Diabetes Care 2004;27:670-5.

32. Trento M, Passera P, Borgo E, et al. A 3-year prospective randomized controlled clinical trial of group care in type 1 diabetes. Nutr Metab Cardiovasc Dis 2005;15:293-301.

33. Wagner EH, Grothaus L, Sandhu N, et al. Chronic care clinics for diabetes in primary care: a system-wide randomized trial. Diabetes Care 2001;24:695-700.

34. Benedetti R, Flock B, Pedersen S, et al. Improved clinical outcomes for fee-for-service physician practices participating in diabetes care collaborative. Jt Comm J Qual Saf 2004;30:187-94.

35. Boegner C, Fontbonne A, Gras Vidal MF, et al. Evaluation of a structured educational programme for type 2 diabetes patients seen in private practice. Diabetes Metab 2008;34:243-9.

36. Bray P, Thompson D, Wynn J, et al. Confronting disparities in diabetes care: the clinical effectiveness of redesigning care management for minority patients in rural primary care practices. J Rural Health 2005;21:317-21.

37. Culhane-Pera K, Peterson K, Crain A, et al. Group visits for Hmong adults with type 2 diabetes mellitus: a pre-post analysis. J Health Care Poor Underserved 2005;16:315-27.

38. Desouza CV, Rentschler L, Haynatzki G. The effect of group clinics in the control of diabetes. Prim Care Diabetes 2010;4:251-4.

39. Dickman K, Pintz C, Gold K, et al. Behavior changes in patients with diabetes and hypertension after experiencing shared medical appointments. J Am Acad Nurse Pract 2012;24:43-51.

40. Dontje K, Forrest K. Implementing group visits: Are they effective to improve diabetes self-management outcomes? J Nurse Pract 2011;7:571-7.

41. Gutierrez N, Gimple N, Dallo F, et al. Shared medical appointments in a residency clinic: an exploratory study among Hispanics with diabetes. Am J Manag Care 2011;17:e212-4.

42. Loney-Hutchinson LM, Provilus AD, Jean-Louis G, et al. Group visits in the management of diabetes and hypertension: effects on gylemic and blood pressure control. Curr Diab Rep 2009;9:238-42.

43. Mallow JA. Diabetes group medical visits and biophysical outcomes of care in uninsured persons with diabetes [dissertation]. Morgantown (WV): West Virginia University; 2011.

44. Pieber TR, Holler A, Siebenhofer A, et al. Evaluation of a structured teaching and treatment programme for type 2 diabetes in general practice in a rural area of Austria. Diabet Med 1995;12:349-54.

45. Raballo M, Trevisan M, Trinetta A, et al. A study of patients' perceptions of diabetes care delivery and diabetes: Propositional analysis in people with type 1 and 2 diabetes managed by group or usual care. Diabetes Care 2012;35:242-7.

46. Reliability and validity of a diabetes quality-of-life measure for the diabetes control and complications trial (DCCT). The DCCT Research Group. Diabetes Care 1988;11:725-32.

47. Stratton IM, Adler A, Neil H. Association of glycaemia with macrovascular and microvascular complications of type 2 diabetes (UKPDS 35): prospective observational study. BMJ 2000; 321:405-12.

48. Kannel WB. Elevated systolic blood pressure as a cardiovascular risk factor. Am J Cardiol 2000;85:251-5.

49. Canadian Diabetes Association 2008 clinical practice guidelines for the prevention and management of diabetes in Canada. Can J Diabetes 2008;S1(Suppl 1):S201.

50. US Department of Health and Human Services. The seventh report of the Joint National Committee on Prevention, Detection, Evaluation and Treatment of High Blood Pressure. Bethesda (MD): The National Heart, Lung and Blood Institute Health Information Center; 2003.

51. Cook NR, Cohen J, Hebert PR, et al. Implications of small reductions in diastolic blood pressure for primary prevention. Arch Intern Med 1995;155:701-9.

52. Gerstein HC, Miller ME, Byington RP, et al.; Action to Control Cardiovascular Risk in Diabetes Study Group. Effects of intensive glucose lowering in type 2 diabetes. $N$ Engl J Med 2008; 358:2545-59

53. Patel A, MacMahon S, Chalmers J, et al.; ADVANCE Collaborative Group. Intensive blood glucose control and vascular outcomes in patients with type 2 diabetes. $N$ Engl J Med 2008;358: 2560-72. 
Affiliations: School of Nursing (Housden, Wong), Centre for Health Services and Policy Research (Wong) and Department of Family Practice, Faculty of Medicine (Wong, Dawes), University of British Columbia, Vancouver BC

Contributors: Laura Housden, doctoral candidate, led the systematic review, conducted the meta-analysis and wrote the first and subsequent drafts of the article. Sabrina Wong and Martin Dawes provided feedback, expertise and direction on the methodology and ensured the accuracy of the data extraction. Sabrina Wong contributed to the selection of articles and provided direction on the assessment of article bias. Martin Dawes assisted with the meta-analysis and sensitivity analysis. All of the authors critically revised the manuscript for important intellectual content and approved the final version submitted for publication.
Funding: No direct funding was received for this study. Laura Housden was supported by a Junior Graduate Trainee Award from the Michael Smith Foundation for Health Research, the Canadian Health Services Research Foundation/Canadian Institutes of Health Research (CHSRF/CIHR) Chair Program in Advanced Practice Nursing, and the CIHR/CHSRF TutorPHC (Transdisciplinary Understanding and Training on Research - Primary Health Care) training program. The sponsors had no role in the design of the study, the collection, analysis or interpretation of the data, the writing of the report or the decision to submit the article for publication.

Acknowledgements: The authors acknowledge Lee Ann Bryant, reference librarian, and Joseph Puyat, doctoral student, University of British Columbia School of Population and Public Health, for their contributions in the preparation of this review. 